\title{
Failure behaviour of a fire protected steel element
}

\author{
Siphesihle Motsa, Georgios Drosopoulos \\ Structural Engineering and Computational Mechanics Group, Discipline of Civil Engineering, University of KwaZulu-Natal, \\ Durban, South Africa \\ 214580281@stu.uk.zn.ac.za \\ DrosopoulosG@uk.zn.ac.za, bttps://orcid.org/0000-0002-4252-6321
}

\begin{abstract}
In the present article the failure behaviour of a steel, beam type element supported against fire by protection boards, is studied. Three dimensional, coupled temperature - displacement, non-linear finite element analysis models have been developed to simulate the unprotected and protected structure. A simple modelling approach is proposed for the investigation of the influence of the gradual failure of fire protection at elevated temperatures, on the structural performance of the system, under thermal and mechanical loads. Yielding of steel is depicted and force displacement diagrams are used to evaluate the ultimate behaviour of the unprotected and protected models. It is shown that for the protected structure, yielding is less severe and the time period up to maximum strength is significantly longer. Eventually, is depicted how failure of the fire protection leads to a gradual reduction of the response, in fire conditions.
\end{abstract}

KEYWORDS. Steel structures; Fire; Protection; Coupled analysis; Finite element analysis.

\section{OPEN ACCESS}

Citation: Motsa, S., Drosopoulos, G., Failure behaviour of a fire protected steel element, Frattura ed Integrità Strutturale, 46 (2018) 124-139.

Received: 21.05.2018

Accepted: 23.07.2018

Published: 01.10 .2018

Copyright: (C) 2018 This is an open access article under the terms of the CC-BY 4.0, which permits unrestricted use, distribution, and reproduction in any medium, provided the original author and source are credited.

\section{INTRODUCTION}

S tructural steel, although is a widely used material, due to its high thermal conductivity rapidly loses its strength when exposed to elevated temperatures. The yield strength and stiffness of steel can be reduced drastically, when exposed to a temperature of $500^{\circ} \mathrm{C}$ or more [1].

To overcome these shortcomings, passive (among others) fire protection systems acting as insulators, are assigned to steel elements. Spray applied fire resistive materials (SFRM), gypsum and cement based, concrete boards are some of the options related to passive fire protection. Concrete, due to its low conductivity, acts as an insulator since it delays the transfer of heat to the steel elements when exposed to elevated temperatures.

Several experimental research studies have shown that fire protection boards improve the resistant of steel when exposed to fire. Composite columns made of partially encased steel sections tested in [2] in fire conditions, failed under flexural buckling, while the concrete encasement played a significant role in preventing local buckling of the flanges. An investigation conducted in [3] concluded that the fire protection of steel columns can easily be damaged in ambient temperatures, and the risk of damage is higher when the protected steel is exposed to cyclic loading. From an 
experimental study presented in [4], it was observed that a greater network of cracks is formed on the side of the concrete exposed to fire and that crack propagation takes place along the thickness. Experimental and numerical studies in [5], revealed that the fire resistance of recycled aggregate concrete-filled square steel tubular columns increases with an increase in the thickness of fire protective coating and a decrease in axial compressive load ratio. In the experimental investigation conducted by [6] it was shown that the steel to concrete interface tends to fail, when exposed to elevated temperatures.

Numerical models have also been proposed, for the investigation of the behaviour of composite and fire protected steel structures [7 - 14]. However, only a relatively small number of articles focusing on the gradual failure of the protection in fire conditions and its impact on the structural behaviour of steel, can be found. Delamination and/or damage of the fire protection material in fire conditions, strongly influence the performance of steel structures. The collapse of the WTC twin towers was partially attributed to the loss of insulation due to high impact and blast loads $[15,16]$.

In [17] the effect of fire insulation delamination on steel structures during fire following an earthquake or an explosion was studied. In the framework of a sequential thermal - structural analysis, a pre-defined delamination area (due to earthquake or explosion), restricted to a small length of the considered model, was adopted from a delamination study presented in [18]. The same authors presented in [19] a numerical model used to investigate the delamination effect of spray-applied fire resistive material (SFRM) under blast loading. In [20] the damage of a fire protection concrete board applied to a steel beam was considered, in the framework of coupled temperature - stress analysis. In [21] a study of the delamination effect during post-earthquake fire on composite steel frames, revealed that delamination of fire protection at the bottom of columns causes a large reduction in the fire resistance time, up to $70 \%$.

In the majority of the published research, the concurrent appearance of mechanical and thermal phenomena is not taken into account. Instead, first a thermal analysis is usually conducted, followed by a structural analysis. Within this framework, phenomena related to damage of the protection and their interaction with thermal/mechanical loads, as the fire event is evolved with time, are not taken into account.

Therefore, the goal of this research is twofold: First, to recommend a simplified modelling technique for the consideration of the effect of the gradual failure of the protection, under fire conditions and mechanical loads. This is an effort towards imitating the behaviour of steel structures in fire conditions, where due to elevated temperatures, re-distribution of forces and failure of some steel members, both gradual damage of the passive protection and mechanical loads arise. Then, to present an insight on the structural performance of steel members under fire and mechanical loads, including among others yielding of steel, as well as reduction of the strength of the system, depicted by force - displacement diagrams.

For the implementation of the mentioned ideas, a non-linear finite element analysis model is developed, where concrete fire protection boards are assigned to one, or more sides of a steel element. Both a standard temperature - time thermal load curve and a force - time mechanical load curve are simultaneously considered in the framework of coupled temperature - displacement finite element analysis.

\section{GENERAL FRAMEWORK OF THE PROPOSED FIRE PROTECTION SCHEME}

A steel, beam type structure with a length equal to $3 \mathrm{~m}$, has been chosen as the structural element of this research. In the perimeter along the length of it, one or more concrete boards are assigned, as fire protection. Between the boards and the steel, a unilateral contact - thermal condition is applied. Thus, opening between the boards and the steel can be freely developed, without any tensile resistance. This assumption relies on the fact that the structural influence of the fire protection board is not to be taken into account in this work. Instead, only its thermal contribution is examined. If at the interface between the protection and the steel some tensile and shear resistance were considered, then the protection would influence structurally, the performance of the steel. In [22] was experimentally shown that the interfacial normal and shear stresses between steel and fire protection coatings are very low (with values of $0.04 \mathrm{MPa}$ and $0.07 \mathrm{MPa}$, respectively). In addition, adopting zero interfacial resistance is a safe assumption.

To account for the influence of the gradual damage of the fire protection due to elevated temperatures on the structural performance of the system, the following, simplified concept is used. Fire is initially applied to the fire protection. Next, an effort of imitating a realistic sequence of phenomena during a fire event, is considered. Thus, after a chosen time period where fire is only applied to the board, the board is expected to fail due to elevated temperatures, and to no longer be able to protect the structure against fire. In that chosen time period, fire is applied to the steel surfaces too, which had initially been protected by the concrete board.

It is worth mentioning that the experimental investigation conducted in [23], indicated that failure of fire protection coatings is related to delamination between the coating and the steel, as well as to the mechanical failure of the protection, 
due to cracking and crushing. Similar phenomena are expected when mechanical and fire loads are applied to steel structures. By using the mentioned modelling technique, the quantification of the performance of the system before and after the failure of the thermal protection, is elaborated.

In the main, steel structural element, an $305 \times 305 \times 118 \mathrm{H}$ section has been assigned [24]. The height of the section is equal to $314,5 \mathrm{~mm}$, the width is $306,8 \mathrm{~mm}$, the thickness of the flange is $18,7 \mathrm{~mm}$ and the thickness of the web is $11,9 \mathrm{~mm}$. The steel is initially considered to be fixed to the ground and have the other end free (cantilever). An alternative model with a simply supported element, is also presented. A concrete board with a thickness equal to $5 \mathrm{~cm}$, which is selected as the fire protection material, is initially assigned to the one flange of steel. Then, two and three concrete boards are applied to the other sides. The different fire protection cases adopted in this work are shown in Fig. 1.
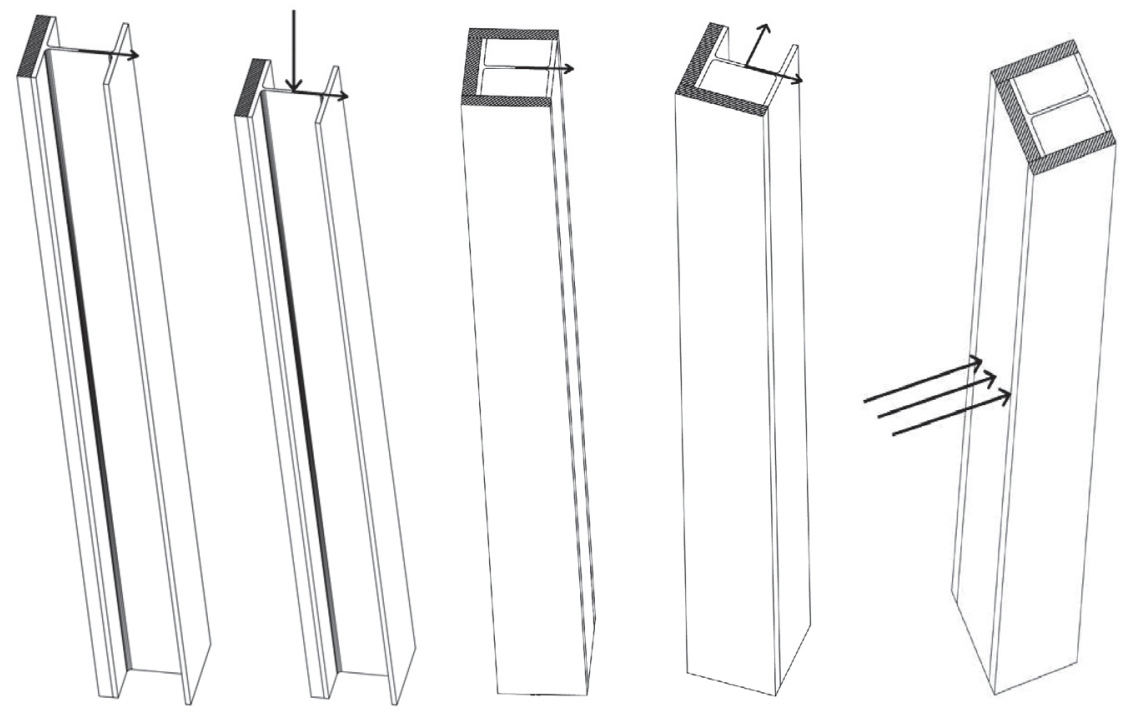

Figure 1: Fire protection schemes and corresponding mechanical loads.

For the numerical analysis, transient, coupled temperature - displacement analysis has been used with ABAQUS commercial finite element software. This type of analysis requires more computational effort, than the uncoupled thermalstructural analysis, where thermal analysis is initially considered and the output of this (temperature variation) is incorporated in a subsequent structural analysis. However, coupled analysis offers the opportunity for a more realistic simulation, since both thermal and structural phenomena are simultaneously examined, similarly to real fire events. Thus, within this type of analysis, concepts such as the interaction between thermal and mechanical loads and their impact on the structural performance of the system, can be depicted.

For all the simulations a fire event of 90 minutes has been considered in the framework of transient thermal-displacement analysis, thus, simulations are evolved in respect to (fire) time. This is implemented by using a standard, ISO 834 temperature - time fire curve [1], which is initially applied to the protected side of the structure. Then, as the fire event evolves, a time period according to which fire protection will not be able to further support the steel against fire, is selected. This time period defines a point in the fire curve, denoting the beginning of the thermal loading on selected steel faces, which were initially protected. By following this procedure, it is stated that the same fire event, passes from the fire protection board, to the steel face.

At each model, fire conditions and mechanical point force(-s) have been considered for the unprotected and protected models, Fig. 1. Among others, models with horizontal point forces assigned to one or two directions, compressive forces and different boundary conditions have been developed.

\section{THERMO-MECHANICAL ANALYSIS}

$\mathrm{T}$ hree main scenarios (and some subcases which are only presented at the results for simplicity) are examined in this article. The first scenario is related to the unprotected steel and the steel protected with one concrete board assigned to the one flange (Fig. 2). In Fig. $2 \mathrm{a}$ is shown that a full fire curve is applied as thermal loading at the shaded flange of the unprotected steel. A full fire curve is also assigned to the concrete board of the protected structure, 
Fig. 2b. However, after a chosen time, the fire curve is transmitted to the protected flange of the steel, due to failure of the board to further protect the structure against fire. In both the unprotected and the protected models, a horizontal force is applied to the top of the steel, while the case of a compressive load is also investigated.
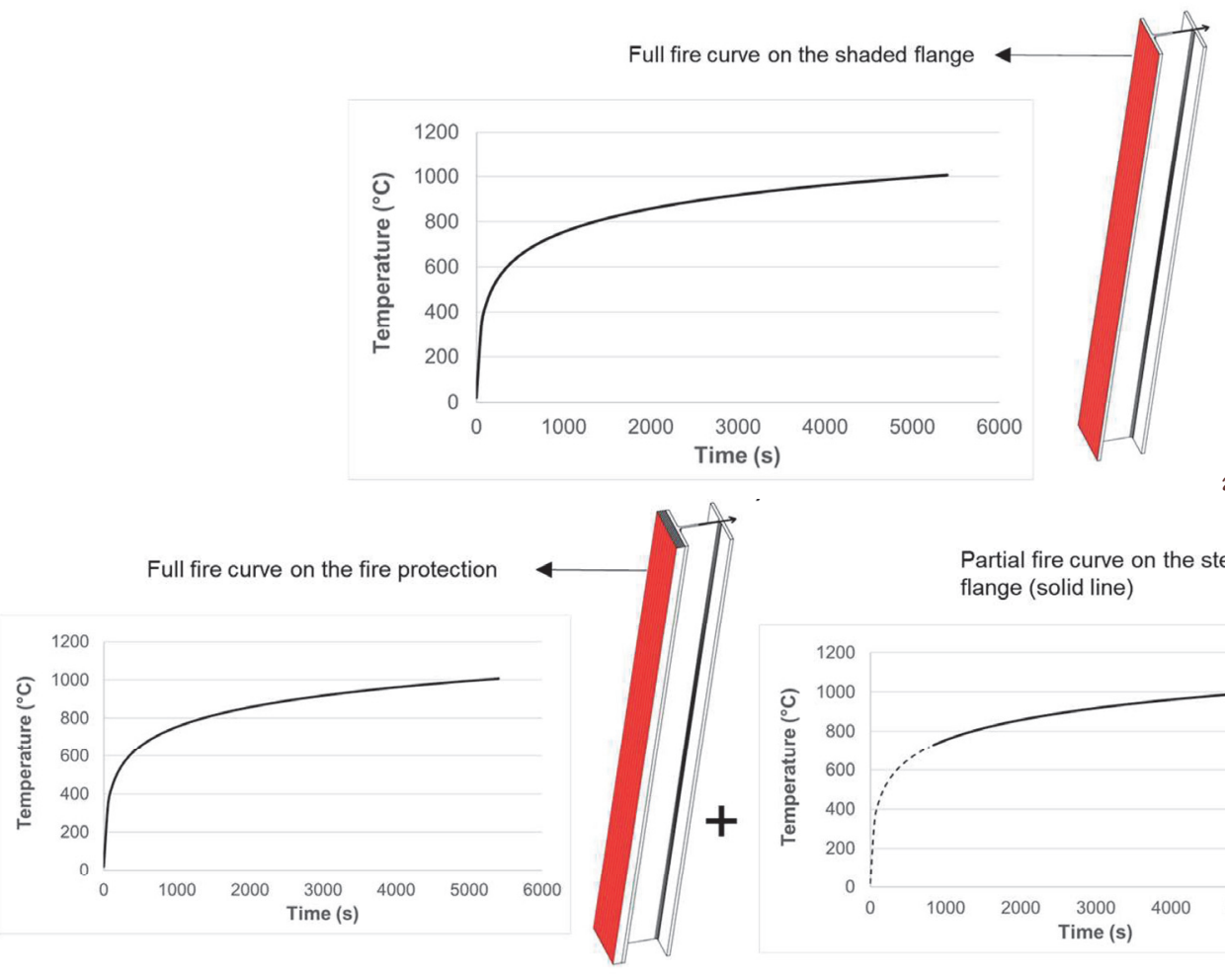

a)

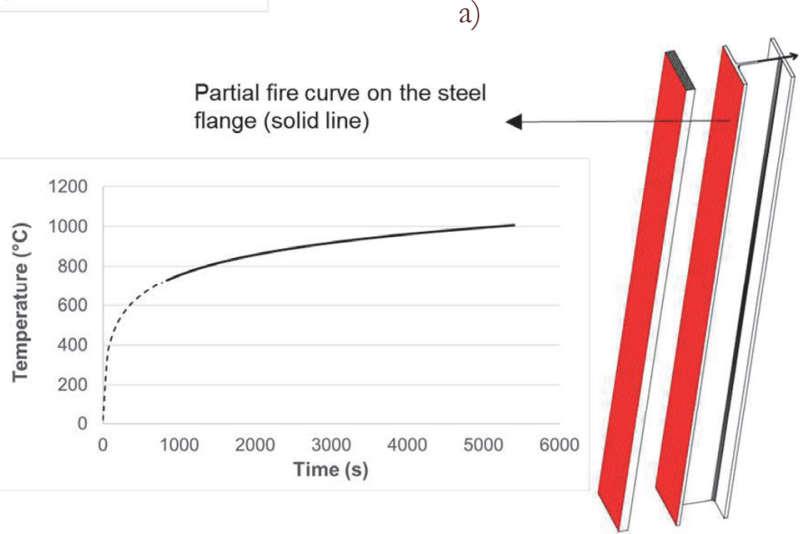

b)

Figure 2: a) Unprotected steel structure, with full fire curve on the one flange b) Protected steel structure with fire curve on the fire protection (full curve) and on the steel flange (partial fire curve).

The second scenario, is related to the usage of more protection boards, covering the steel, (Fig. 3b). According to the previous description, after a chosen time, thermal loading passes to the steel faces in the perimeter of the structure, which were initially covered. An unprotected structure, with thermal loading applied to corresponding faces of steel, is also considered (Fig. 3a). Both models are assigned a horizontal mechanical load. The third scenario incorporates bi-axial mechanical loading (Fig. 4).

In the mentioned models, a mechanical load varying linearly in respect to (fire) time, is applied to the steel. Thermal boundary conditions (ambient temperature of $20^{\circ} \mathrm{C}$ ) have also been assigned to the top and bottom section of the structure.

A variation of the thermal conductivity and specific heat of steel in respect to temperature, has been adopted from [1]. Similarly, the thermal conductivity and specific heat of the concrete fire protection mentioned in [27], have been used in this article.

An S355 grade of steel has been assigned to the steel element [25, 26]. Then, the degradation of the strength of the steel at elevated temperatures has been considered, using Eurocode's statements ([1]). In particular, the stress-strain curves shown in Fig. 5 have been adopted in the finite element analysis models, to depict the reduction of the strength of steel due to fire. Reduction of the elasticity modulus of steel in respect to temperatures has also been considered, according to Eurocode 3.

\section{DETAILS OF THE FINITE ELEMENT MODEL}

$\mathrm{T}$ he mesh of the finite element model which is used in the numerical simulation for the steel and the concrete fire protection, is shown in Fig. 6. The mesh of the steel consists of 47808 coupled temperature - displacement brick elements (73984 nodes), with four degrees of freedom per node (three displacements plus one temperature). 


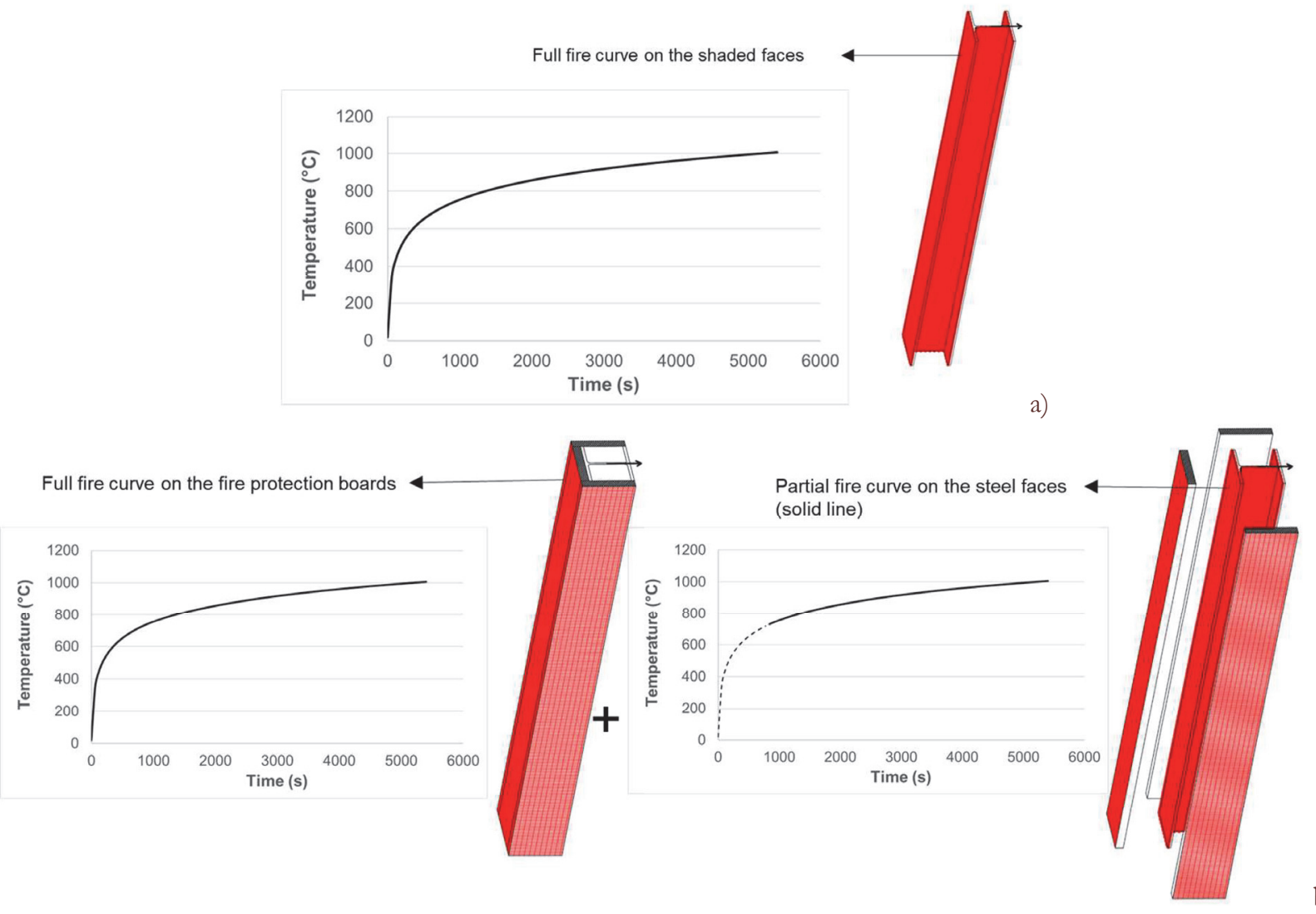

b)

Figure 3: a) Unprotected steel structure, with full fire curve on three side faces of the steel b) Protected steel structure with fire curve on the fire protection (full curve) and on the three side faces of steel (partial fire curve).
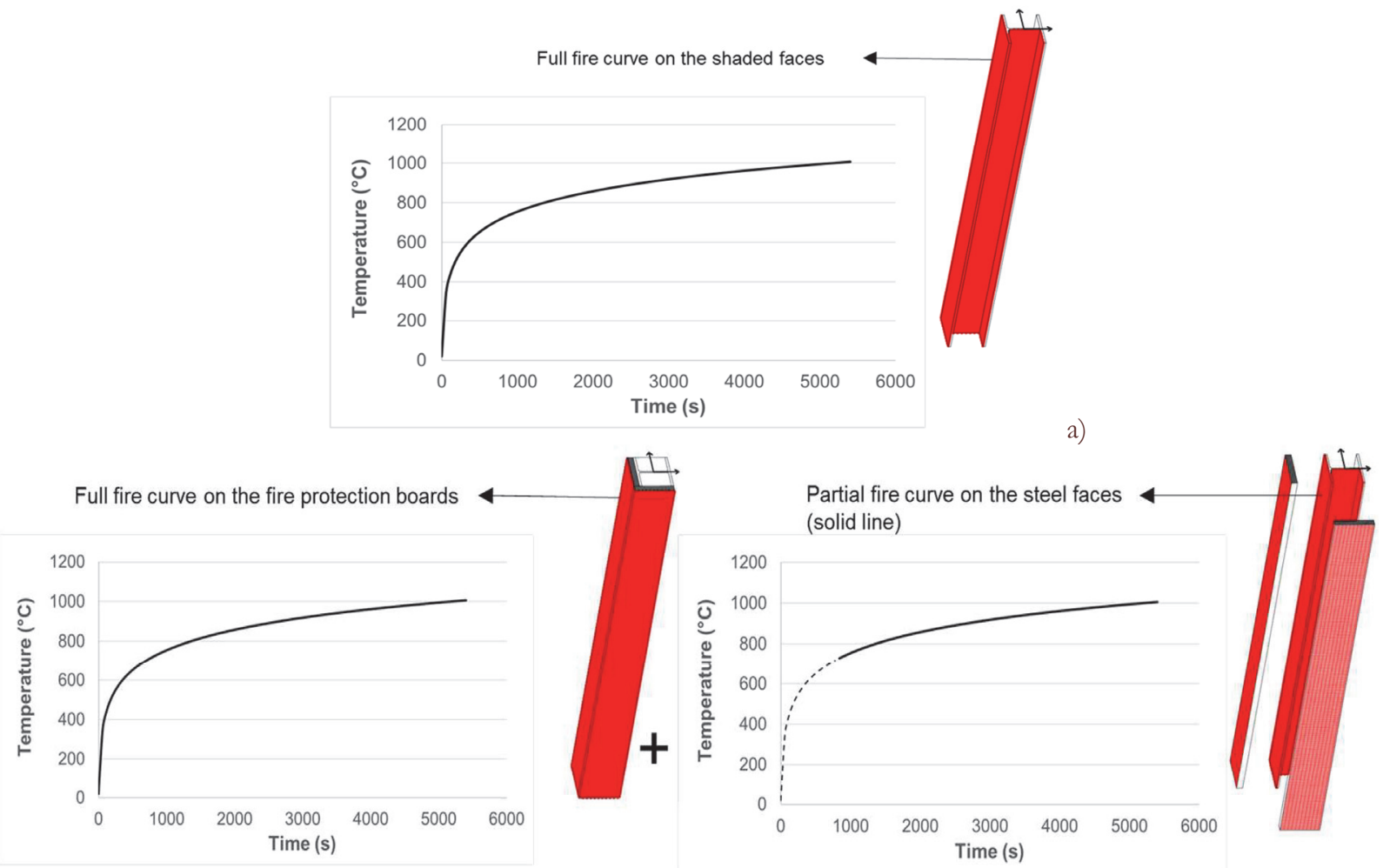

b)

Figure 4: a) Unprotected steel structure, with full fire curve on two side faces of the steel b) Protected steel structure with fire curve on the fire protection (full curve) and on the two side faces of steel (partial fire curve). 


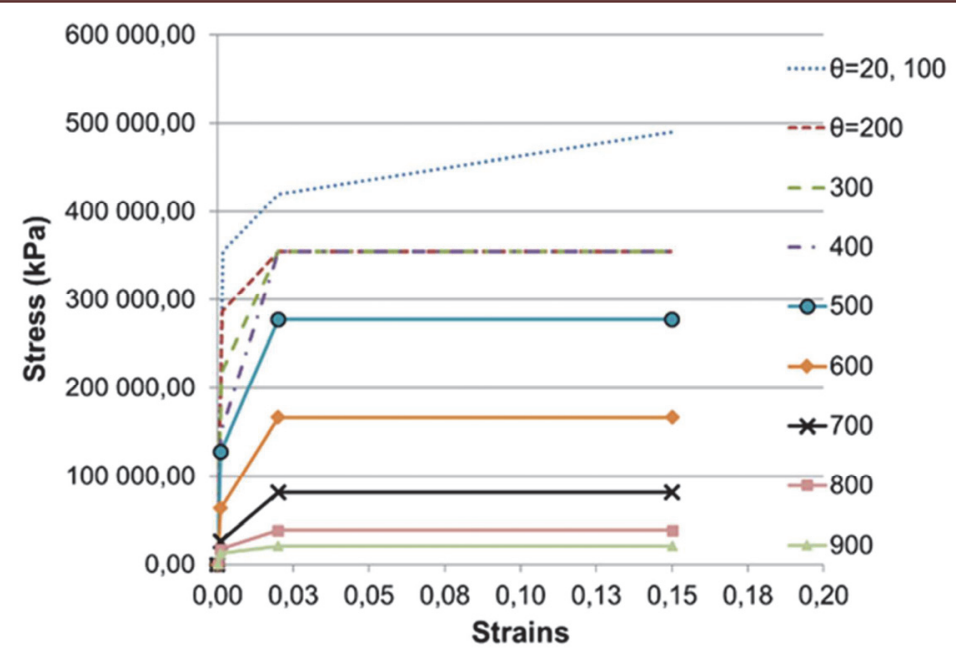

Figure 5: Degradation of the stress-strain laws of steel at elevated temperatures $\left({ }^{\circ} \mathrm{C}\right)$

A von Mises plasticity model is assigned to depict plastic yielding of steel, according to the diagrams shown in Fig. 5. Big displacements and unilateral-thermal contact at the protection-steel interface(-s) are also used in the models. A relatively big value has been used for the thermal conductance between the protection and the steel. This is to ensure that once in contact, thermal conditions pass from the protection to the steel. The Newton-Raphson incremental-iterative procedure is used for the solution of the considered problems.

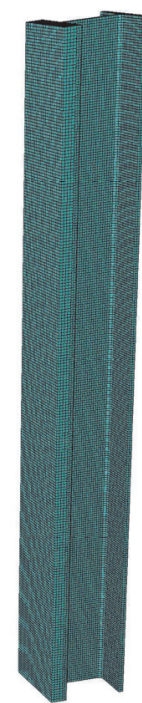

Figure 6: Mesh of the structure with one fire protection board

\section{RESULTS AND DISCUSSION}

\section{One protection board}

7 he first scenario under investigation, considers the unprotected and the protected structure with one board at the flange (Fig. 2). The force - displacement diagrams received from the unprotected and the protected structure are given in Fig. 7. According to the diagram received from the unprotected structure, are recognized three phases related to the structural behaviour of the tested element at elevated temperatures under mechanical loading. The first phase (up to point A shown in the diagram), represents the first branch where a high temperature gradient (according to ISO 834 temperature - time fire curve adopted from [1] is applied to the flange of the steel. That represents approximately 5 minutes of the fire event, where from the temperature - time curve ([1]) an increase in temperatures from 
20 to $580^{\circ} \mathrm{C}$ is denoted. In Fig. $8 \mathrm{a}$ is shown that at this time, elevated temperatures have been distributed through the thickness of the steel flange and tend to spread in the web.

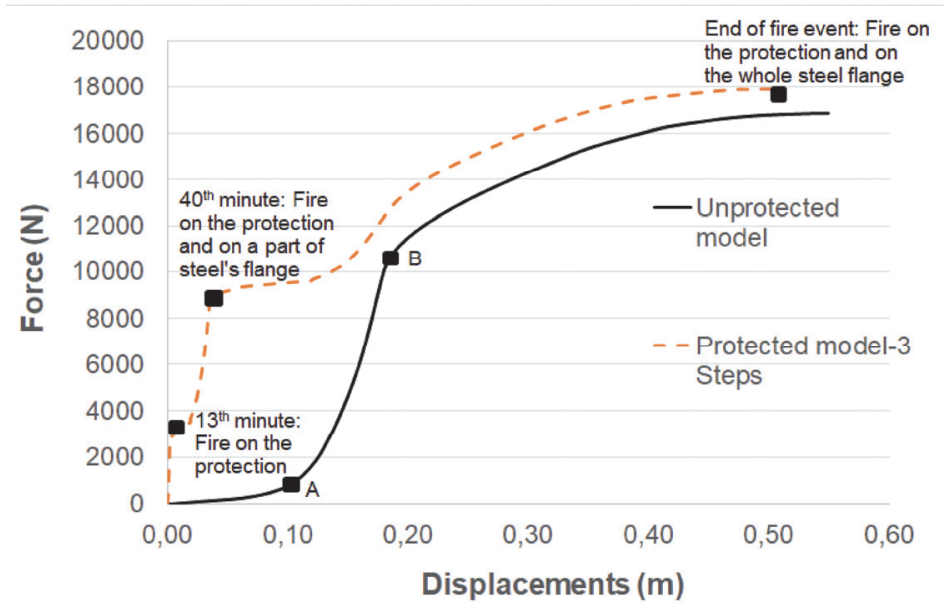

Figure 7: Force - displacement diagrams for the unprotected and the fire protected structure (one fire protection board)

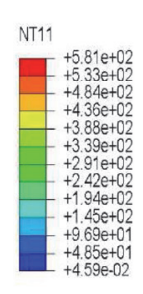

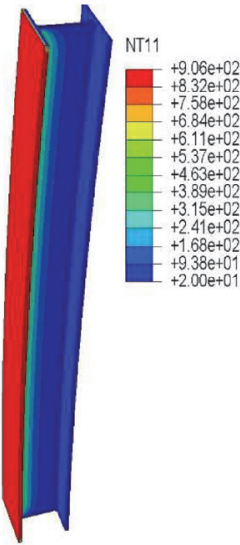

a)

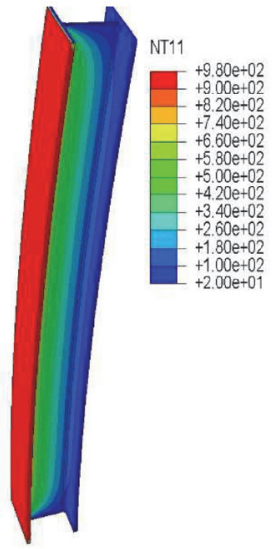

b)

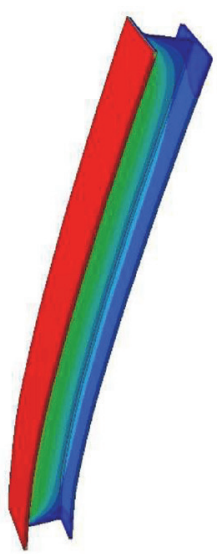

c)

Figure 8: Temperature $\left({ }^{\circ} \mathrm{C}\right)$ distribution at the unprotected structure at the a) $5^{\text {th }}$ b) $46^{\text {th }}$ c) 75 th minute (end of analysis), of the fire event.

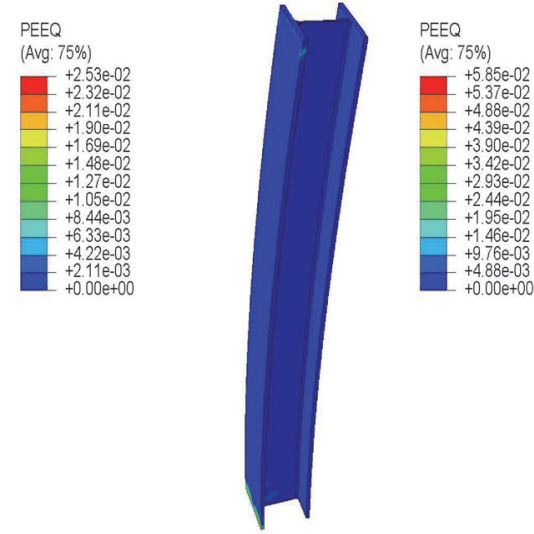

a)

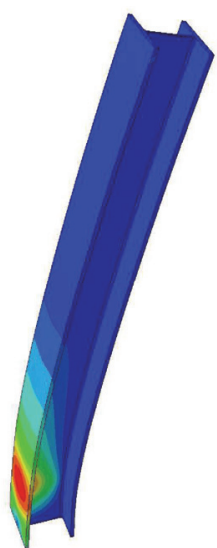

b)

Figure 9: Equivalent plastic strain distribution at the unprotected structure at the a) $46^{\text {th }}$ b) $75^{\text {th }}$ minute (end of analysis), of the fire event. 
From point $\mathrm{A}$ to point $\mathrm{B}$ of the diagram of the unprotected model shown in Fig. 7 (time between the 5th and 46th minute), there is an increase in the inclination of the diagram. From Fig. $8 \mathrm{~b}$ is shown that there is a lower temperature gradient during this phase, thus, a temperature increase of $325^{\circ} \mathrm{C}$ in the flange of steel takes place during these 41 minutes. Up to point B of the diagram, only small, local yielding of the steel is observed (Fig. 9a). However, from point B to the end of analysis, a rapid increase of steel yielding takes place (Fig. 9b) and the force - displacement diagram becomes almost horizontal, denoting failure of the structure.

For the analysis of the protected structure, is decided that for the first 13 minutes of the simulation, the fire curve is assigned only to the fire protection board. During this step, thermal energy passes with conduction through the interface between the steel and the protection, at the areas where no delamination takes place. It is mentioned that simultaneously, a mechanical load is applied to the top of the structure (Fig. 2), causing delamination between the protection and the steel (Fig. 10). From 13th to 40th minute of the simulation, and due to the fact that delamination has started, the fire curve is applied to a part of the steel flange (initially protected), close to the top of the structure, where delamination is most severe. Eventually, from the 40th minute to the end of the considered fire event, the fire curve is assigned to the rest of the protected flange. Thus, it is decided that the concrete board will not be able to resist more thermal loads, after a fire duration of 40 minutes.

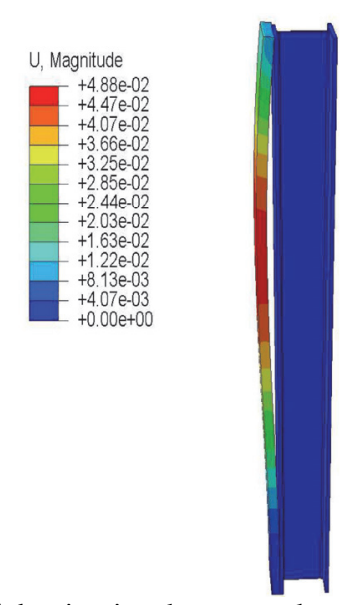

Figure 10: Displacement $(\mathrm{m})$ distribution depicting delamination between the steel and the concrete board at the $13^{\text {th }}$ minute of the fire event

It is worth mentioning that this assumption, which is considered for the majority of the applications presented in this article, is based on the fact that Eurocode 2 states that "concrete in excess of $500^{\circ} \mathrm{C}$ is assumed not to contribute to the load bearing capacity of the member, whilst the residual concrete cross-section retains its initial values of strength and modulus of elasticity" ([27]). Indeed, after 40 minutes, temperatures between $880^{\circ} \mathrm{C}$ (face of concrete where the fire curve is applied to) and almost $400^{\circ} \mathrm{C}$ (opposite face) have been developed along the thickness of the concrete board (Fig. 11a). In any case, further research and usage of experimental date shall be used for the proper evaluation of the thermal failure of concrete material surrounding steel structures.

The behaviour of the protected structure is depicted by the corresponding force - displacement diagram shown in Fig. 7 with the dashed line. The phases which are obtained due to the gradual application of fire in the protection board and the steel, are recognized in this diagram. It is clear that an important improvement in the stiffness of the system arises for the first 40 minutes of the fire event, in comparison with the unprotected structure. However, after the 40th minute, due to the assumption that the protection cannot provide further thermal support, the behaviour of the protected structure is only slightly improved in respect to the unprotected one, thus, both diagrams follow similar paths.

In Figs. 11 and 12 the temperature and plastic strain distribution are presented for the protected model. Fig. 12b shows that the ultimate yielding takes place on the bottom of the structure, where maximum bending moments arise.

Two more cases have been studied in relation to the model with one fire protection board. The fire curve is applied to the fire protection (step-1) and to the total flange of the steel (step-2), thus, the middle step of the previous description, with fire on a part of the steel flange, is ignored. The corresponding diagrams shown in Fig. 13, are obtained from two alternative thermal load cases. In case a, fire is applied on the whole flange of the steel after the 40th minute of the fire event (less conservative scenario) while in case b, fire is on the steel on the 13th minute (conservative scenario). 
The force - displacement diagrams for the protected models, start with an initial stiffer branch, followed by a horizontal part attributed to the fact that fire passes on steel, then an ascending part, until the final, almost horizontal ending depicting failure of the structure. Similar temperature and plastic strain distributions, as the ones presented in Figs. 11, 12, are obtained from these simulations.

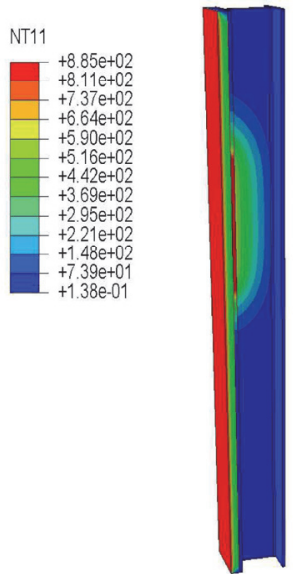

a)

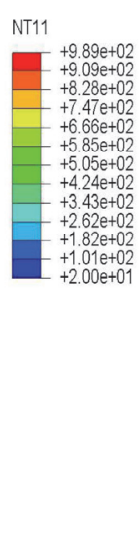

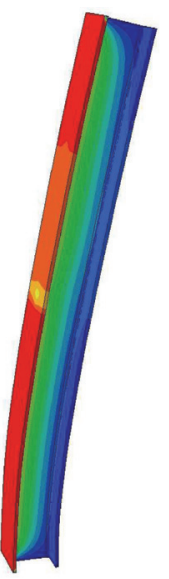

b)

Figure 11: a) Temperature $\left({ }^{\circ} \mathrm{C}\right.$ ) distribution at the protected structure at the a) $40^{\text {th }}$, b) $80^{\text {th }}$ minute (end of analysis), of the fire event

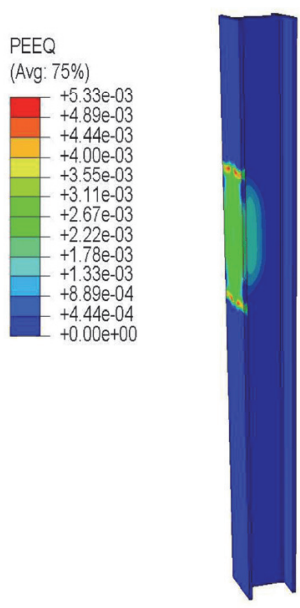

a)

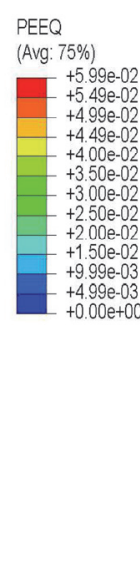

$+5.99$

$+5.49 \mathrm{e}-02$

$+4.99 \mathrm{e}-0$

$+3.50 \mathrm{e}-02$

Figure 12: Equivalent plastic strain distribution at the protected structure at the a) $40^{\text {th }}$ b) $80^{\text {th }}$ minute (end of analysis), of the fire event

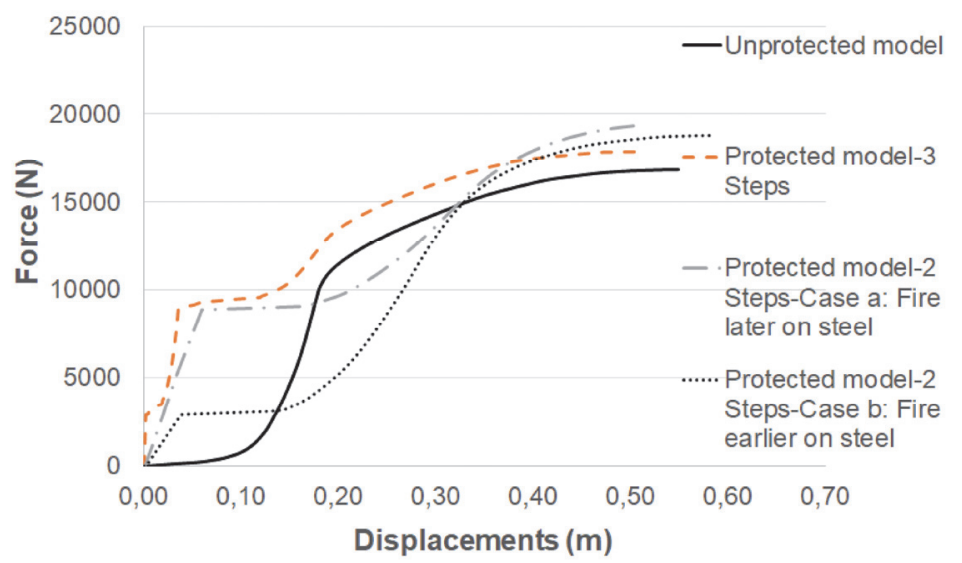

Figure 13: Force - displacement diagrams for the unprotected and the fire protected structure (one fire protection board) with alternative thermal scenarios 
Compressive load

To take into account the influence of compressive forces, an analysis introducing one additional, pre-existing step, is considered for both the unprotected and the protected models. In this step, a compressive load is applied to the top of the element. Then at subsequent steps, the fire curve and the horizontal mechanical load are considered for the unprotected and the protected model with one protection board at the flange of the steel (Fig. 2).

It is noted that in the framework of the Newton-Raphson incremental-iterative procedure, which is used in this article for the representation of the non-linear behaviour of the considered models, post-buckling behaviour cannot be depicted. For this, alternative numerical solutions, using for example the arc-length approach, are necessary. This becomes more complicated when coupled thermal - displacement analysis is used, since the arc-length approach may not be supported for this type of analysis.

For these reasons, authors did not investigate the post-buckling behaviour of the elements with compressive loads in fire conditions. However, the results at the end of analysis, related to the behaviour just before buckling, are mentioned in this section.

Three compressive load cases were considered, as a fraction of the critical compressive force calculated using Euler's formula for a cantilever column. In the first case, a compressive force equal to $77 \%$ of the critical Euler's force was used. Simulation of the unprotected model showed that when fire and the horizontal force were considered (after completion of the step with the compressive force), analysis was terminated at early stages, depicting almost zero strength.

Results were improved for the second and the third compressive load cases, with compressive forces equal to $36 \%$ and $15 \%$ of the Euler's force. For these cases, some strength was obtained in fire conditions. Still, this strength was significantly smaller than the strength derived from the same models, without compressive forces. For the unprotected model, the second and third compressive load cases resulted in 3,5\% and 15\% strength respectively, in respect to the strength of the same model without compressive forces. For the protected model and the third compressive load case, a strength equal to $47 \%$ of the strength of the same model without compressive forces was received.

In Fig. 14 is shown the comparison of the force - displacement diagrams, between the unprotected and the protected model, for the smallest compressive load, equal to $15 \%$ of the Euler's force. The difference between the two diagrams is significant, depicting a clearly improved behaviour of the protected structure. The duration of each simulation until failure leads also to the same conclusion. The unprotected model fails after 11,3 minutes, contrary to the protected model which fails after 41 minutes. This means that when compressive forces are present, the fire protection can be quite beneficial for the structural system.

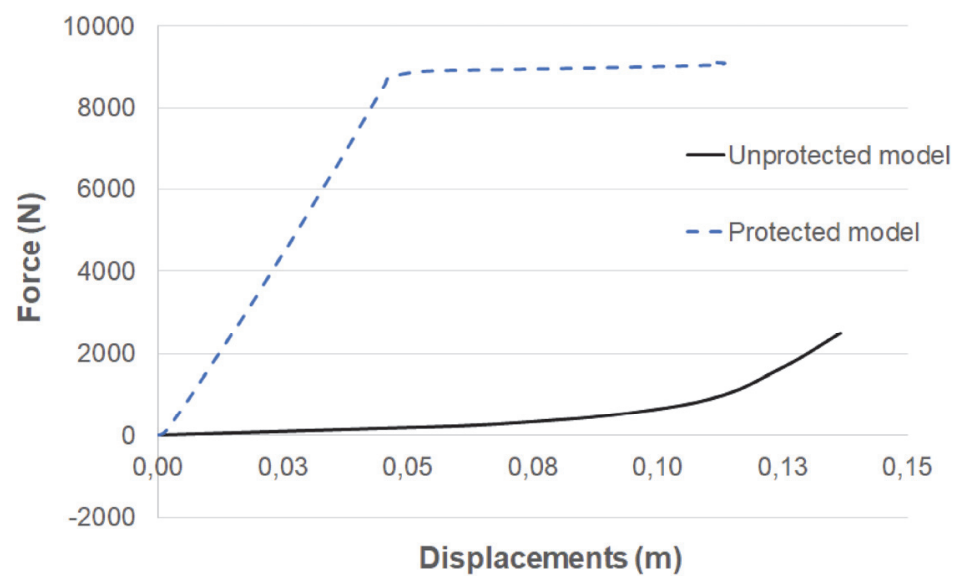

Figure 14: Force - displacement diagrams for the unprotected and the fire protected structure (one fire protection board) with compressive loading

\section{Fire protection in the perimeter of the structure}

Towards protecting more sides of the structural element and investigating the influence of elevated temperatures on multiple surfaces of the unprotected and the protected structure, the model shown in Fig. 3 has been developed, with fire protection in the perimeter of the structure. The fire curve is initially applied to the protection (first 40 minutes), then it is added to the protected flange of the steel (up to 60th minute) and eventually it is applied also to the other side surfaces of the steel (up to the end of analysis).

From the force - displacement diagrams obtained from these simulations (shown in Fig. 15) is derived that the protected model results in a significantly improved behaviour, in comparison to the unprotected one. Contrary to the previously 
mentioned cases, where fire was applied only to one flange of the steel, it seems that thermal loading in multiple faces leads to a significantly improved strength of the protected structure. In particular, an increase of the maximum force of the protected structure equal to $96 \%$ of the maximum force of the unprotected one is obtained. The corresponding ratio for the case of thermal loading on one flange of the steel was only equal to $15 \%$. Furthermore, the strength of the structure (protected and unprotected) is significantly lower, when multiple surfaces are under fire conditions (Figs. 13 and 15).

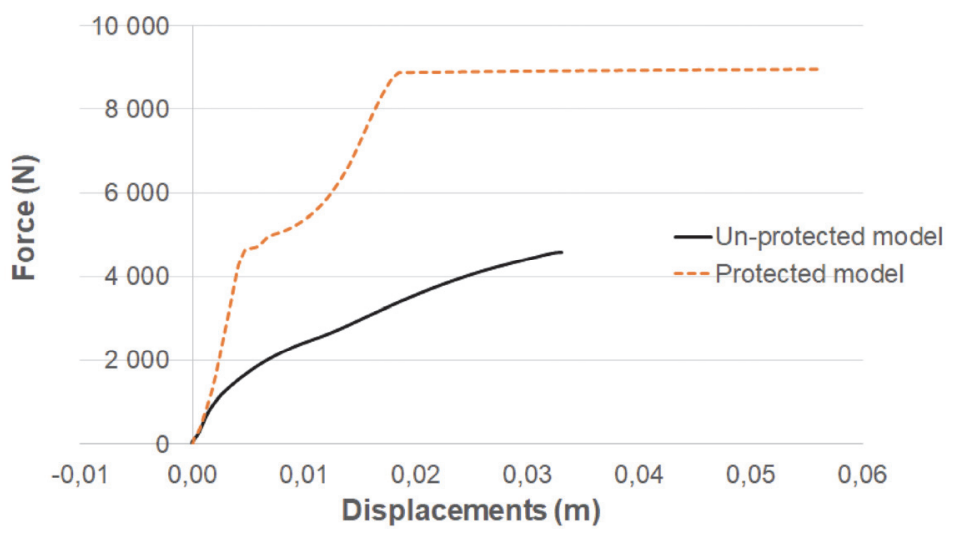

Figure 15: Force - displacement diagrams for the unprotected and the fire protected structure (three fire protection boards at three sides of the structure)

In Figs. 16 and 17 are shown the temperature and the plastic strain distribution for the unprotected and the protected structure. An almost uniform plastic strain distribution arises for the unprotected structure at the end of analysis (Fig. 16b).

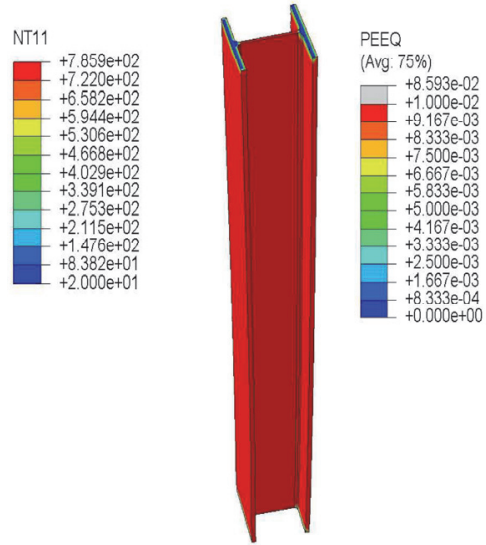

a)

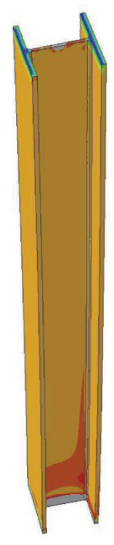

b)

Figure 16: a) Temperature $\left({ }^{\circ} \mathrm{C}\right)$, b) Plastic strain distribution for the unprotected element, at the end of analysis (fire in the perimeter of the structure)

\section{Behaviour of the structure under bi-axial loading}

To depict the influence of bi-axial horizontal loading, steel is protected with two concrete boards (Fig. 4) and mechanical loads are applied along Y ("strong") and X ("weak") axis. The fire curve is applied initially to the protection boards, after 40 minutes (40th minute) to the flange of steel (which was initially protected) and after 20 minutes (60th minute) to the other side of steel (initially protected by the second board).

According to the force - displacement diagrams shown in Fig. 18 for loading along each direction, a clear improvement arises in the strength of the structure, in respect to the unprotected one. The unprotected structure reaches the final strength and displacement, after 27 minutes, while the protected one reaches a significantly higher maximum force in lower displacements, after 60 minutes. 


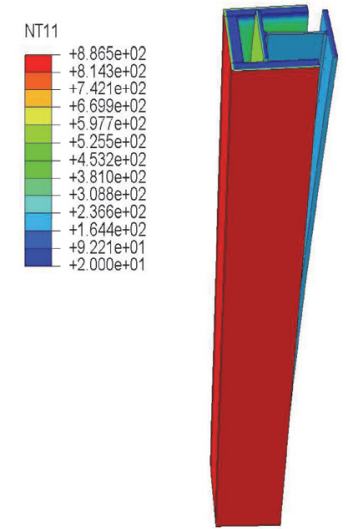

a)

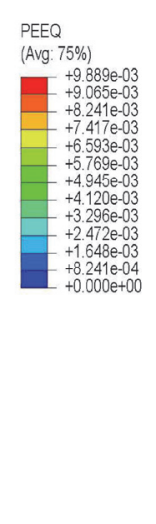

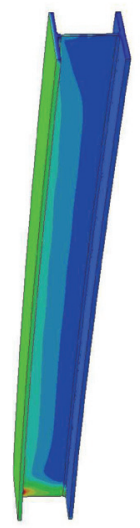

b)

Figure 17: a) Temperature $\left({ }^{\circ} \mathrm{C}\right)$, b) Plastic strain distribution for the protected element, at the end of analysis (fire in the perimeter of the structure)

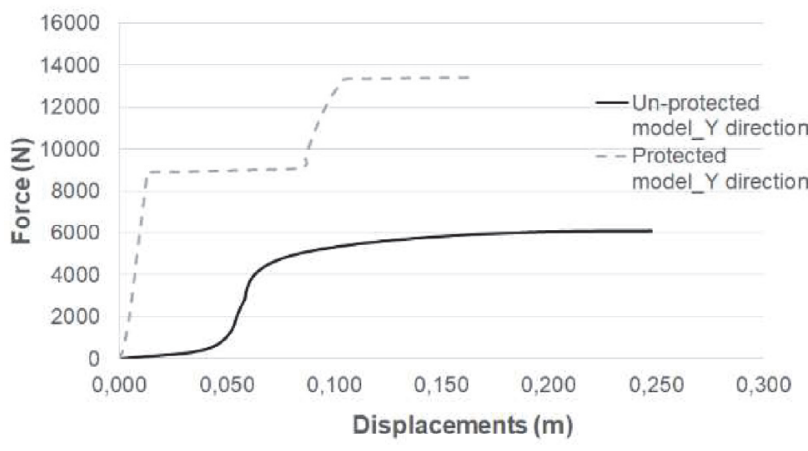

a)

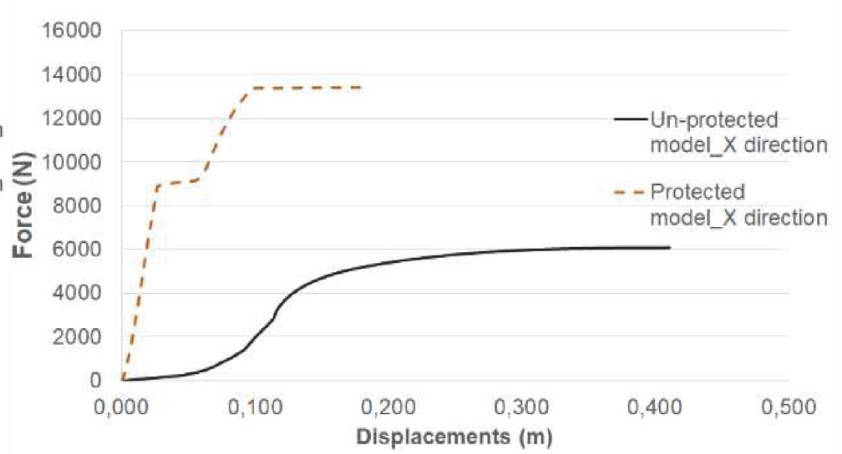

b)

Figure 18: Force - displacement diagrams a) along the "strong" axis Y, b) along the "weak" axis X, for the unprotected and the fire protected structure with two concrete boards and bi-axial loading

In Fig. $19 \mathrm{~b}$ is shown that the web of the structure is severely deformed and damaged in the unprotected model, due to biaxial loading. A less severe image of yielding on the steel (and particularly in the web of the steel) is depicted in Fig. 20b, for the protected model. In Figs. 19a and 20a temperature distributions for the unprotected and the protected models, are also shown.

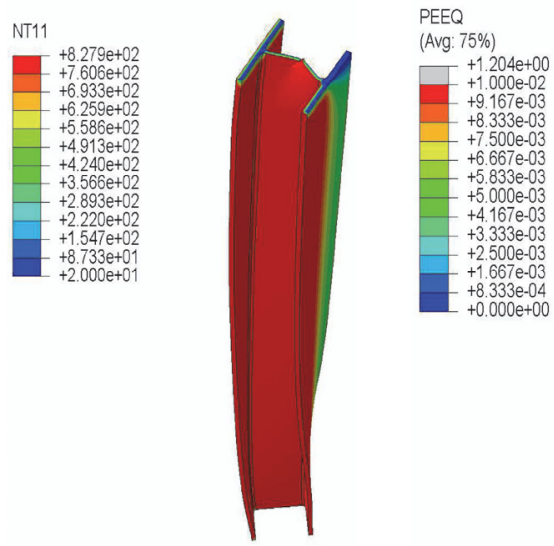

a)

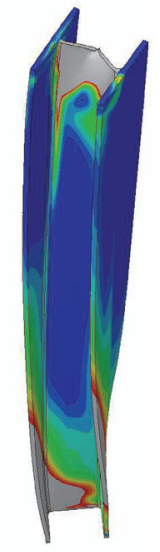

b)

Figure 19: a) Temperature $\left({ }^{\circ} \mathrm{C}\right)$, b) Plastic strain distribution for the unprotected element, at the end of analysis (bi-axial loading) 


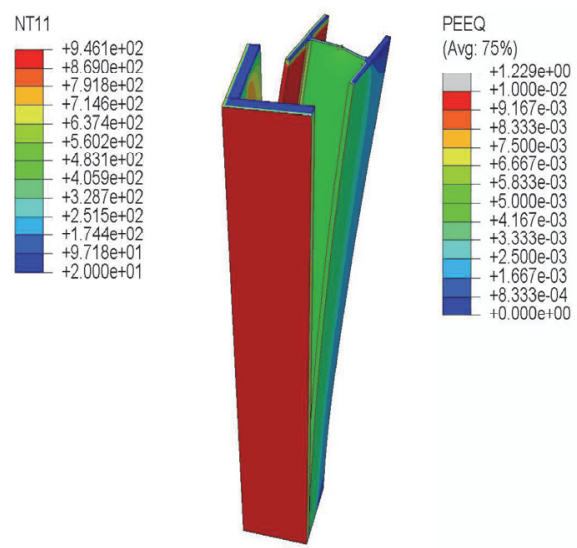

a)

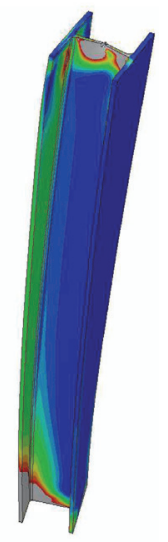

b)

Figure 20: a) Temperature $\left({ }^{\circ} \mathrm{C}\right)$, b) Plastic strain distribution for the protected element, at the end of analysis (bi-axial loading).

\section{Behaviour of the structure with different boundary conditions (simply supported)}

In the last analysis of this work, the boundary conditions of steel are changed and the structure from cantilever becomes simply supported. A distributed mechanical loading varying linearly in respect to time, is applied to the middle of the span of steel (Fig. 1). Distributed instead of point load is used, to minimize local yielding of steel at the position of the load. The fire curve is applied to the perimeter of steel, in the unprotected model. In the protected model, fire is applied to the three protection boards for the first 40 minutes, to the one flange of steel for the next 20 minutes and to the rest of the steel surfaces for the last 30 minutes (end of the fire event).

From the force - displacement diagrams shown in Fig. 21, it is concluded that the strength of the structure obtained from the protected model at the end of analysis is more than twice the strength of the unprotected one. In addition, the protected model fails after 41 minutes of the fire event, in approximately one third of the displacement which is developed in the unprotected structure (which appears after only 17,8 minutes of the fire event).

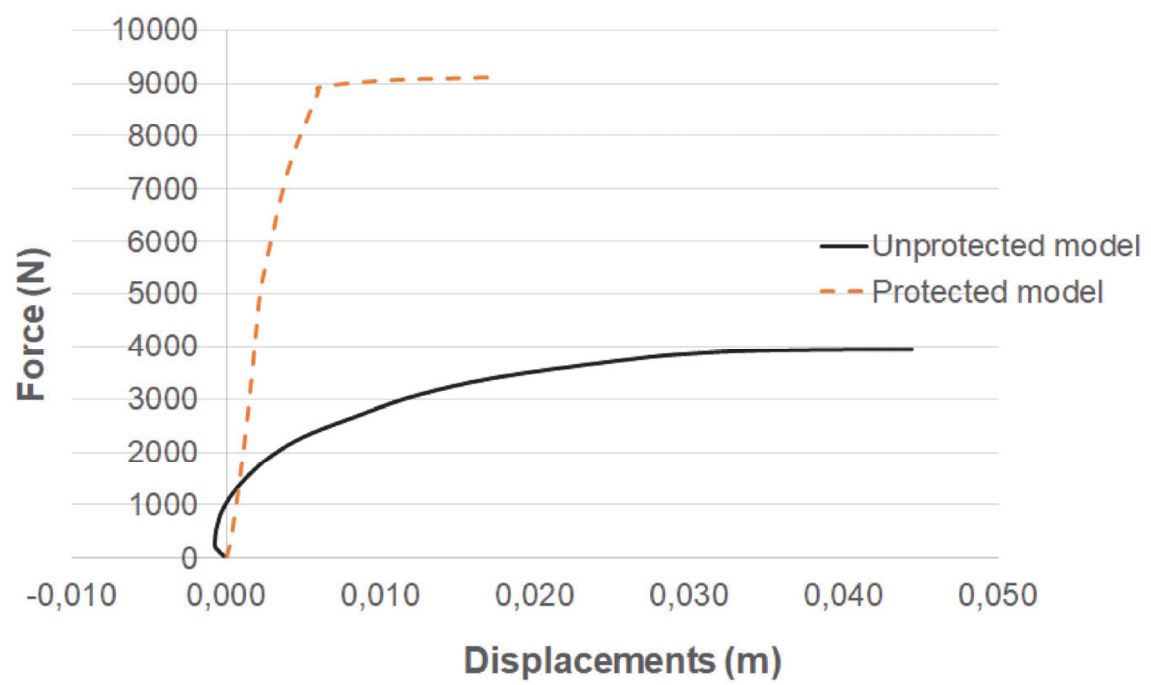

Figure 21: Force - displacement diagrams for the unprotected and fire protected simply supported structure

In Figs. 22 and 23 the temperature and plastic strain distribution, obtained from the unprotected and the protected model are shown. According to Fig. 22b, a severe yielding of steel arises at the flange and the web, below the distributed mechanical load at the middle of the unprotected structure. On the contrary, yielding of the protected steel arises mainly on the flange, localized in the area of the distributed loading. Only small plastic strains appear on the web of the protected structure, in comparison to the unprotected one. 


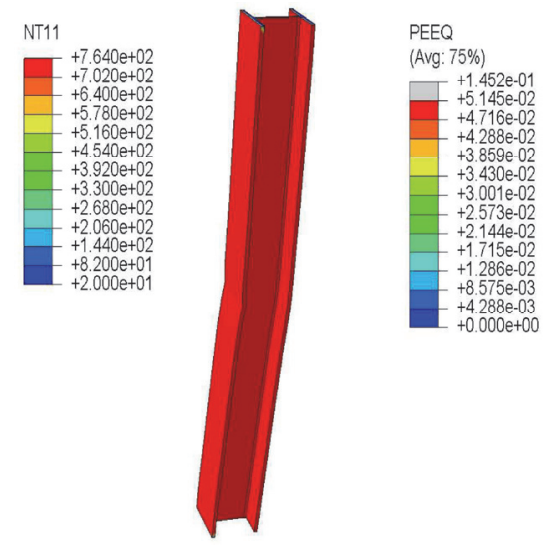

a)

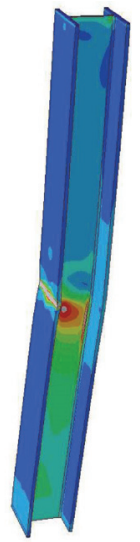

b)

Figure 22: a) Temperature $\left({ }^{\circ} \mathrm{C}\right)$, b) Plastic strain distribution for the unprotected, simply supported element, at the end of analysis

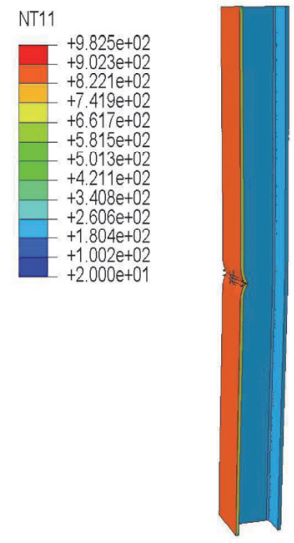

a)

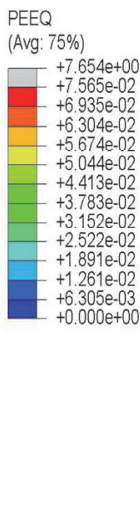

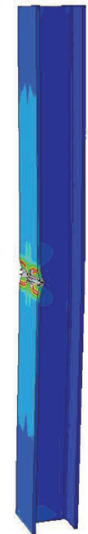

b)

Figure 23: a) Temperature $\left({ }^{\circ} \mathrm{C}\right)$, b) Plastic strain distribution for the protected, simply supported element, at the end of analysis

\section{CONCLUSIONS}

$\mathrm{F}$ undamental goal of this research is to offer a simple modelling technique, able to quantify the structural performance of protected steel structures in fire conditions. A modelling approach, based on non-linear finite element analysis, is proposed for the simulation of steel, beam type elements with and without fire protection, under thermal and mechanical loads, both varying over the time. The passive protection used in this work consists of concrete boards but gypsum or any other material could similarly be used.

First, based on literature, or possible experimental data, the time period that the fire protection cannot further support the structure against fire, is defined. Then, a fire curve taken from Eurocode is gradually applied to the protection and (after this selected time period) to the steel. This is a natural evolution of phenomena taking place in a real fire event: the protection initially protects the structure, but after some time it is damaged and is no longer able to support the structure against fire.

In the majority of the published research, delamination between fire protection - steel and the damaged area of the protection are pre-defined in previously established numerical analysis and are considered to be constant during the fire event. On the contrary, in this work an effort is made towards simulating the effect of the gradual damage of the protection during fire, on the steel. Thus, the damage/delamination of the fire protection are not considered to be constant during the thermo-mechanical analysis. Instead, the effect of the gradual damage of one or several protection boards, in different times of the fire event, can be considered.

Non-linear, transient, coupled stress - displacement finite element analysis is used to implement the described concept. When the fire curve is applied only to one flange of the unprotected and the protected steel, a clear increase in the 
stiffness of the protected structure arises, during the time that the protection is considered to be undamaged. When the protection is considered to be totally damaged, the ultimate strength of the protected structure is slightly higher than the unprotected one. However, when fire passes to steel through more than one side surfaces, then the strength received from the protected model is significantly higher than the strength of the unprotected model.

In horizontal bi-axial loading, the web of the unprotected structure suffers from severe yielding, contrary to the protected steel which depicts a better behaviour. Furthermore, the presence of compressive forces proves to be quite important for the behaviour of steel under fire. For big compressive forces close to Euler's critical load, the unprotected structure fails at early stages of the simulation, while for smaller compressive forces, its behaviour is better. However, for the same compressive forces, the performance of the protected structure is significantly improved. An important increase in the strength of the protected system is also received when a simply supported, instead of cantilever, steel element is considered. For this case, severe yielding of the unprotected steel arises on the flange and the web at the middle of the structure.

Another important parameter which is recorded in this work, is the time period until the maximum strength and displacement of steel are reached. An increase in the time until failure of the protected structure from 23 to 33 minutes, has been observed for several scenarios, in comparison to the unprotected one.

This work can be extended by applying the main idea to more complex systems, starting from steel connections and proceeding with bigger steel structures. Another challenge, is the simulation of the failure of fire protection boards, under thermal and mechanical loads, by using a proper constitutive law.

\section{REFERENCES}

[1] Eurocode 3 (2001). Design of Steel Structures - Part 1-2: General Rules - Structural Fire Design, Brussels: European Committee for Standardization.

[2] Correia, A.J.M. and Rodrigues, J.P.C. (2011). Fire resistance of partially encased steel columns with restrained thermal elongation, Journal of Constructional Steel Research, 67, pp. 593-601.

[3] Wang, W.-Y., Li, G.-Q. and Kodur, V. (2012). Approach for modeling fire insulation damage in steel columns, Journal of Structural Engineering, 139, pp. 491-503.

[4] Mindeguia, J.-C., Pimienta, P., Carré, H. and Borderie, C.L. (2013). Experimental analysis of concrete spalling due to fire exposure, European Journal of Environmental and Civil Engineering, 17, pp. 453-466.

[5] Yang, Y.-F., Zhang, L. and Dai, X. (2016). Performance of recycled aggregate concrete-filled square steel tubular columns exposed to fire, Advances in Structural Engineering (SAGE), pp. 1-17.

[6] Wang, W.-H., Han, L.-H., Tan, Q.-H. and Tao, Z. (2017). Tests on the steel-concrete bond strength in steel reinforced concrete (SRC) columns after fire exposure, Fire Technology, 53, pp. 917-945.

[7] Milke, J.A., Ryder, N. and Wolin, S. (2003). Analyses of the impact of loss of spray-applied fire protection on the fire resistance of steel columns, Fire Safety Science, 7, pp. 1025-1036.

[8] Nadjai, A., Petrou, K., Han, S. and Ali, F. (2016). Performance of unprotected and protected cellular beams in fire conditions, Construction and Building Materials, 105, pp. 579-588.

[9] Wang, P., Xia J. and Du, Q. (2016). Temperature rise of a protected steel column exposed to fire from two adjacent sides, Fire Technology, 52, pp. 1887-1914.

[10] Ellobody, E. and Young, B. (2016). Behaviour of composite frames with castellated steel beams at elevated temperatures, Advances in Structural Engineering (SAGE), pp. 1-17.

[11] Bezas, M.Z., Nikolaidis, Th.N. and Baniotopoulos, C.C. (2017). Fire protection and sustainability of structural steel buildings with double-shell brickwork cladding, Procedia Environmental Sciences, 38, 298 - 305.

[12] Neuenschwander, M., Knobloch, M. and Fontana, M. (2017). Modeling thermo-mechanical behavior of concretefilled steel tube columns with solid steel core subjected to fire, Engineering Structures, 136, pp. 180-193.

[13] Rackauskaite, E., Kotsovinos, P. and Rein, G. (2017). Structural response of a steel-frame building to horizontal and vertical travelling fires in multiple floors, Fire Safety Journal, 91, pp. 542-552.

[14] Navrátil, J., Číhal, M., Kabeláč, J., Štefan, R. (2017). Nonlinear analysis of reinforced and composite columns in fire, Frattura ed Integrità Strutturale, 39, pp. 72-87.

[15] American Society for Testing and Materials (ASTM) (2011). Standard Test Method for Cohesion/Adhesion of Sprayed Fire-Resistive Materials Applied to Structural Members, PA: ASTM E736, 3.

[16] NCSTAR (2005). Final Report on the Collapse of the World Trade Center Towers, Principal Findings, 175, pp. 1-6. 
[17] Arablouei, A and Kodur V (2016). Effect of fire insulation delamination on structural performance of steel structures during fire following an earthquake or an explosion, Fire Safety Journal, 84, pp. 40-49.

[18] Kodur, V. and Arablouei, A (2015). Effective properties of spray-applied fire-resistive material for resistance to cracking and delamination from steel structures, Construction and Building Materials, 84, pp. 367-376.

[19] Arablouei, A. and Kodur, V. (2016). Modeling delamination of fire insulation from steel structures subjected to blast loading, Engineering Structures, 116, pp. 56-69.

[20] Zografopoulou, K. and Mistakidis, E. (2017). Numerical simulation of the behaviour of steel members with damaged SFRM fire protection coatings at elevated temperatures, EUROSTEEL, Copenhagen, Denmark.

[21] Suwondo, R., Gillie, M, Cunningham, L. and Bailey, C. (2018). Effect of earthquake damage on the behaviour of composite steel frames in fire, Advances in Structural Engineering (SAGE), pp. 1-16.

[22] Chen, S., Chu, J. and Li, G.Q. (2010). A study on damage mechanism of thick fireproof coating for steel member subjected to monotonic loading, In: Proceedings of the 6th International Conference on Structures in Fire, USA, pp. 130-138.

[23] Chen, S., Jiang, L., Usmani,. A, Li, G..-Q and Jin, C. (2015). Damage mechanisms in cementitious coatings on steel members under axial loading, Construction and Building Materials, 90, pp. 18-35.

[24] Southern African Steel Construction Handbook (2016). 8th Edition, 2nd printing, Southern African Institute of Steel Construction.

[25] Eurocode 3 (2001). Design of Steel Structures - Part 1.1: General Rules and Rules for Buildings, Brussels: European Committee for Standardization.

[26] South African National Standard (SANS 10162-1: 2011). The structural use of steel Part 1: Limit-states design of hotrolled steelwork.

[27] Eurocode 2 (2004). Design of Concrete Structures - Part 1-2: General Rules - Structural Fire Design, Brussels: European Committee for Standardization. 